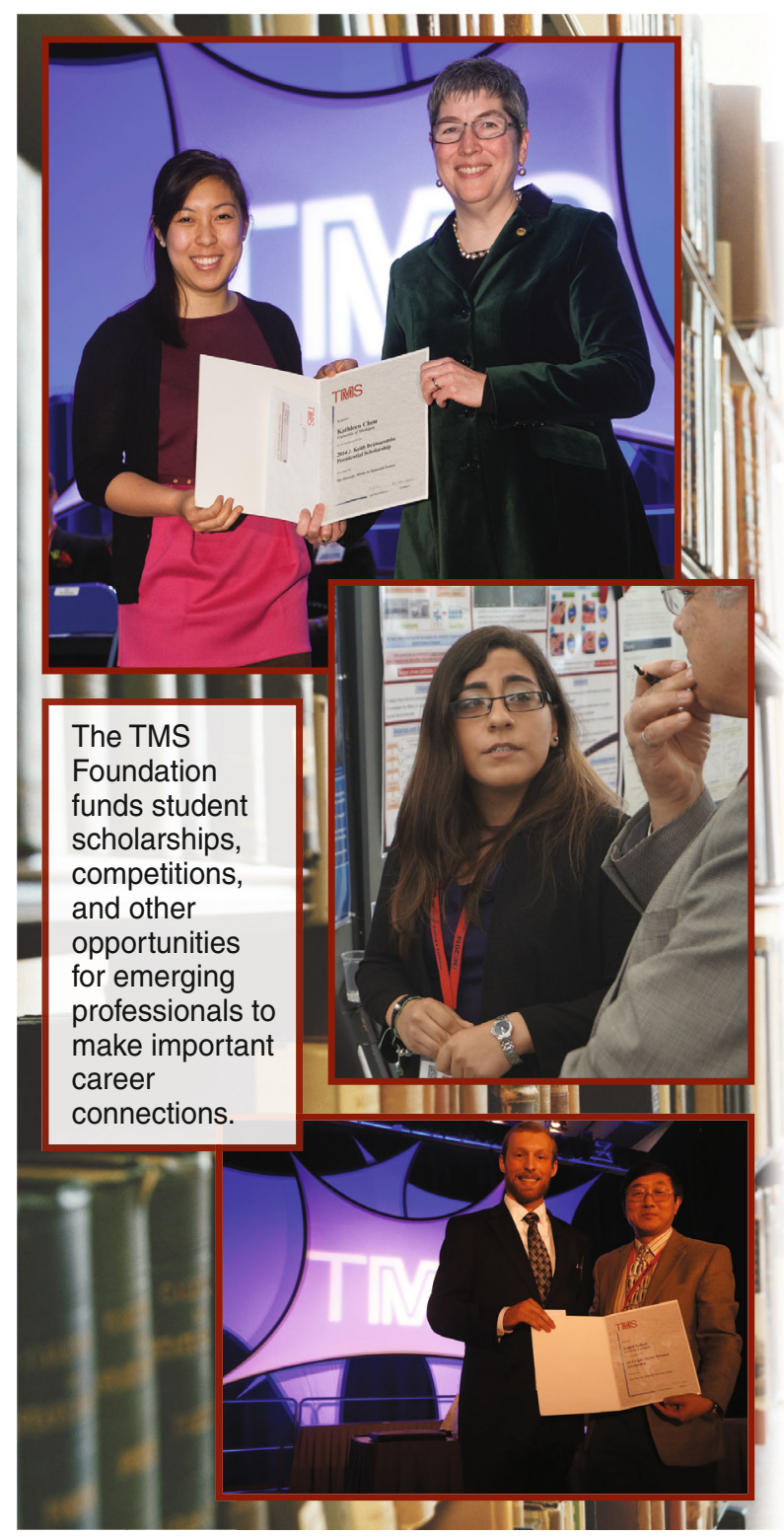

\title{
TMS Celebrates Its Scholars
}

\section{Kaitlin McMahon}

Money isn't everything and it certainly can 't buy happiness; these things we know. But for young college students trying to make a name for themselves, receiving a TMS Foundation scholarship does much more than help finance a college education. Above all else, many students value the endorsement of their work and use this as motivation to pursue even greater goals. Their enthusiasm to broaden their minds and push the limits of what is possible is inspirational. You'll see this enthusiasm as well as a theme of humble pride and gratitude woven into the stories of the 2015 student winners on the following pages.

In addition to the tuition assistance and honor of being named a TMS scholarship winner, students receive travel funds so that they may attend the TMS 2015 Annual Meeting \& Exhibition (TMS2015) to accept their award. Many students also recognize this as an invaluable opportunity to network with other students and professionals, making connections that will impact their lives for years to come.

The TMS Foundation is proud to celebrate the academic achievements of students in the minerals, metals, and materials professions. Most students will receive their award at events scheduled throughout TMS2015, March 15-19, in Orlando, Florida. After you have read about the newest class of scholarship recipients, make sure to congratulate them personally at TMS2015, and remind them: "It always seems impossible until it's done." -Nelson Mandela

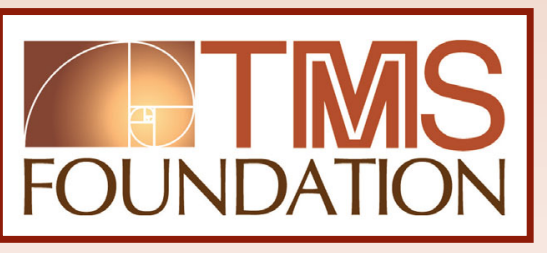

The TMS Foundation launched its first ever Annual Appeal in November 2014, inviting the entire TMS community to make a difference in the lives of our newest professionals and ensure the future vitality and impact of our field. A few of the Foundation's success stories are shared in this article by our most recent student scholarship winners. But there are many, many others. The Annual Appeal opens the conversation on what the Foundation has been able to accomplish as a result of generous donations, as well as what will be necessary to sustain and grow the impact that it has had on the profession.

\section{Be Part of the Next Success Story: Support the 2014 TMS Foundation Annual Appeal}

When you receive your TMS Foundation 2014 Annual Appeal information, please consider it carefully, particularly in the context of what TMS might have contributed to your own career. This is a great chance to "pay it forward" by supporting the Foundation's very particular mission in developing the next generation of minerals, metals, and materials scientists and engineers. As Garry Warren, 2011 TMS president, Foundation trustee, and Founding Member of the TMS Foundation Gold Society, observed, "TMS has given so much to me. The least I can do is give back by supporting the work of the Foundation so that future generations can benefit as I did." 


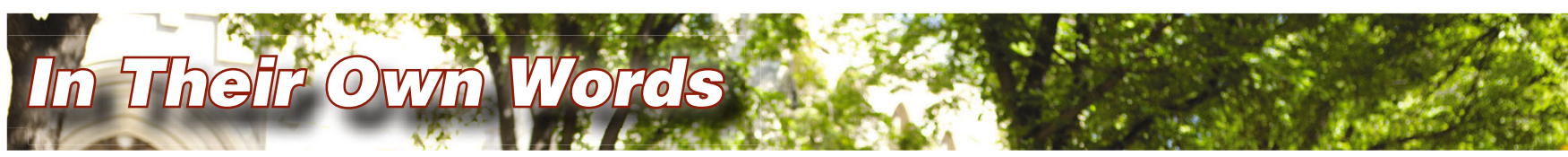

\section{J. KEITH BRIMACOMBE PRESIDENTIAL SCHOLARSHIP}

Awarded to outstanding sophomore or junior students majoring in metallurgical engineering, materials science and engineering, or minerals processing/extraction programs

\section{Thomas Chrobak}

\section{University of Wisconsin-Madison}

"This scholarship from TMS is greatly appreciated, and I am glad I could be recognized for the hard work and dedication I have demonstrated in materials science.
Having a Material Advantage membership has been an awesome experience because I have had the opportunity to witness commercial and academic applications of materials science. This has taught me what it means to be a materials engineer, and has made me excited for what is to come after graduation. I am looking forward to using the knowledge and skills I have learned throughout my education and work experience in a most useful way working as a professional materials scientist, and I accept this award as a reminder to keep up the good work."

\section{EXTRACTION \& PROCESSING DIVISION (EPD) SCHOLARSHIPS}

Awarded to outstanding sophomore or junior students majoring in the extraction and processing of minerals, metals, and materials

\section{Molly Mentzer}

\section{University of Wisconsin-Madison}

"The scholarship awarded to me through the TMS

Foundation will allow me to worry less about the financial aspects of the upcoming school year, and put my time and interests into my newly appointed position as president of the Material Advantage chapter at the University of Wisconsin-Madison. This scholarship also gives me a sense of pride and added security that I have found a major that fits both my interests and my abilities. I am excited to relay the many opportunities of Material Advantage through TMS to other undergraduate students I see on a daily basis so they, too, can experience financial and educational support like this."

\section{Sonja Postak}

\section{Massachusetts Institute of Technology}

"This award will allow me to continue pursuing my education at the Massachusetts Institute of Technology, funded primarily by myself and my parents, who have always placed a large value on the education of their children. But with the ever-rising cost of tuition, they have been forced to fund my education instead of saving for retirement or investing in my younger siblings' college education fund. I am indebted to them for this investment, but must also pay them back after graduation so that my siblings can attend the college of their choosing. The TMS Foundation has lightened the burden on me and my family and for that I am very grateful.”

\section{Jordan Dick}

\section{South Dakota School of Mines \& Technology}

"I am very thankful to the TMS Foundation for providing this scholarship, and I am humbled that I was chosen as the recipient. I am a student athlete, and though I do receive an athletic scholarship, it is not enough to pay for school. Being tied up with basketball all year long, I am unable to work during the school year. This scholarship allows me to go to school and pursue my career of being a metallurgical engineer."

\section{Allen Holmquist}

\section{South Dakota School of Mines \& Technology}

“The TMS Foundation's scholarship will allow me to spend more time at school focusing on my studies. This scholarship will give me the opportunity to network with professionals in the field, which will be invaluable as I look to progress in my future endeavors as a metallurgical engineer."

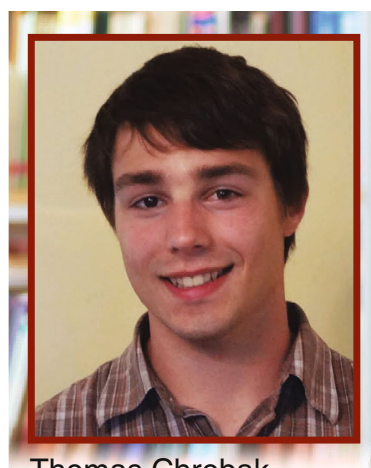

Thomas Chrobak
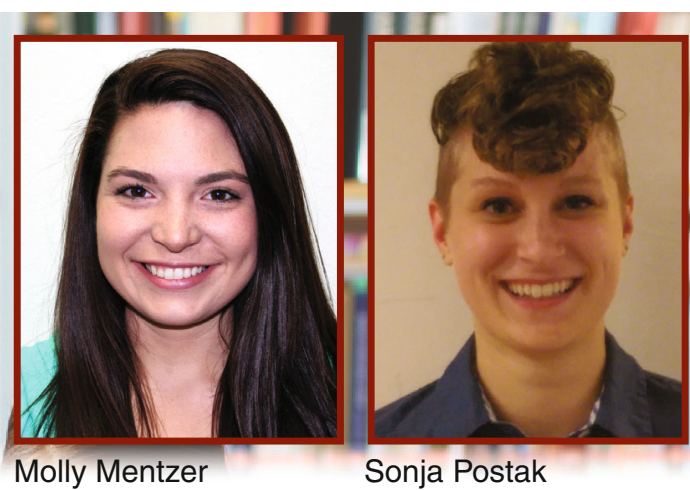

Sonja Postak

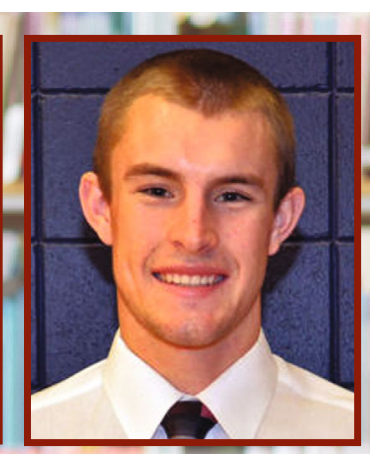

Jordan Dick

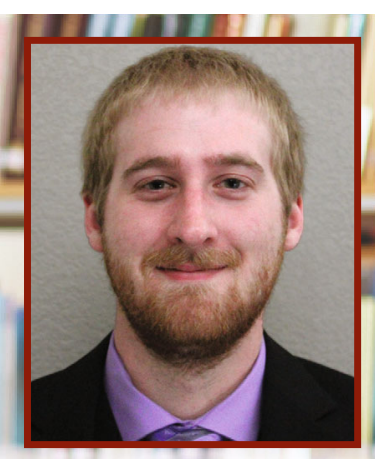

Allen Holmquist 


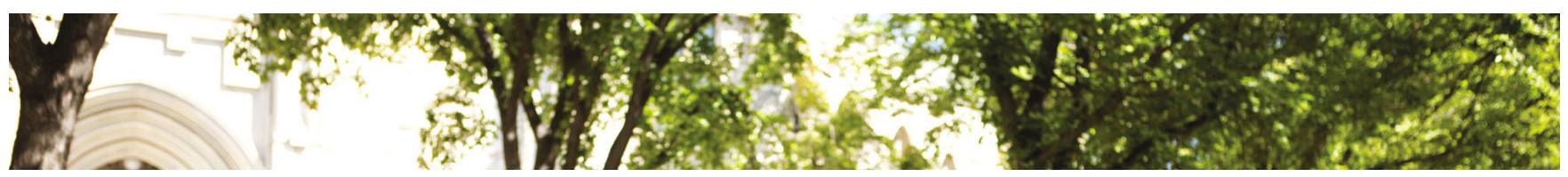

\section{LIGHT METALS DIVISION (LMD) SCHOLARSHIPS}

Awarded to outstanding sophomore or junior students majoring in metallurgical and/or materials science and engineering with an emphasis on both traditional and emerging light metals

\section{Taylor Brown}

\section{University of Alabama at Birmingham}

"I am very thankful for this great opportunity provided by the TMS Foundation. To me, this is more than just a monetary award. This scholarship grants me the ability to not have to work while in school this year. Engineering school can be a very challenging task and to be given this scholarship means that I can focus solely on my studies instead of being burdened by the costs of post-secondary education."

\section{Aaron Kelley}

University of Alabama at Birmingham

"The LMD scholarship will provide me with a means to attend several conferences around the nation, which will help increase my knowledge, experience, and connections within the metals industry. The TMS Foundation has given me the opportunity to act as a student representative who can help promote the excellence, strength, and reputation of my department as well as my university. The conference proceedings which will be donated to my university library will not only benefit me, but it also will provide fellow students, who are unable to attend TMS2015, with a resource to broaden their knowledge and exposure to various metals that may not be taught in the classroom."

\section{Douglas Fraser}

University of Wisconsin-Madison

I must thank the TMS Foundation for their tremendous assistance in helping me obtain my education. This contribution allows me to look beyond the classroom for exciting opportunities in research and industry. As an LMD scholar, I am now further motivated to make academic achievements and set my personal goals higher knowing that I am now capable of meeting such objectives."

\section{MATERIALS PROCESSING \& MANUFACTURING DIVISION (MPMD) SCHOLARSHIPS}

Awarded to outstanding sophomore or junior students majoring in metallurgical and/or materials science and engineering with an emphasis on manufacturing from product design to production, integrating process control technology into manufacturing, and basic applied research into key materials technologies that impact manufacturing processes

\section{Alyx Kahn}

\section{Clemson University}

"Receiving the MPMD scholarship will assist my academic success within polymeric materials during my senior year at Clemson University. It will also help support me financially after graduation by defraying some of my expenses and allow me to focus more on my academic work. The TMS Foundation had provided numerous resources and networking opportunities that have better prepared me for my future within the materials science field. The foundation also continues to invest in the future of the materials profession, and I hope to stay involved in TMS and be able to give back to the organization."

\section{Alexandra Glover}

\section{Michigan Technological University}

"This award reduces the possibility that I will need to take out a student loan during the school year. Additionally, it will allow me to focus on my research with additive manufacturing technologies."

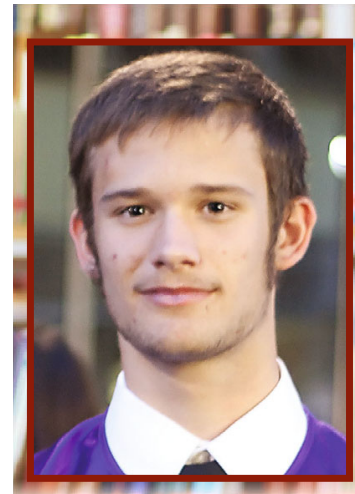

Taylor Brown

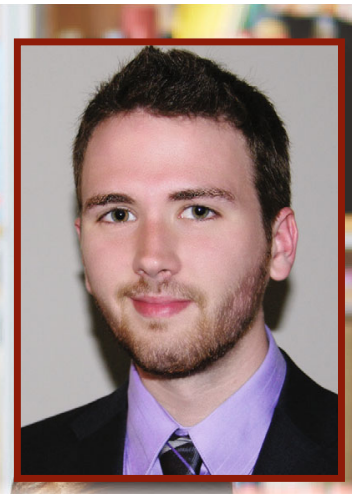

Aaron Kelley

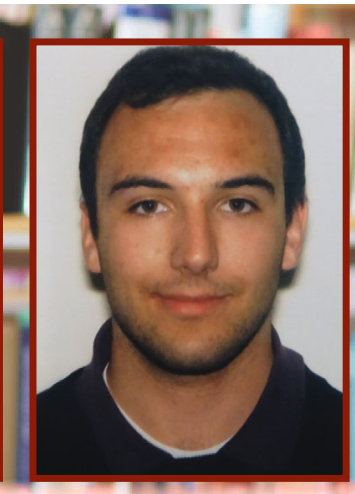

Douglas Fraser

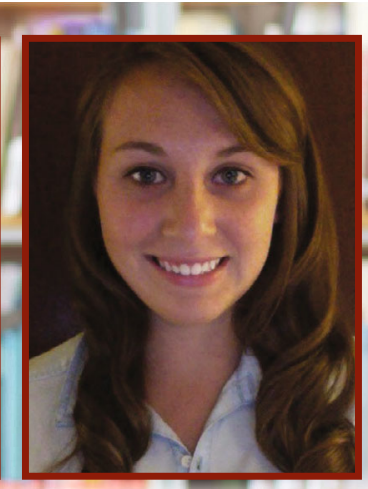

Alyx Kahn

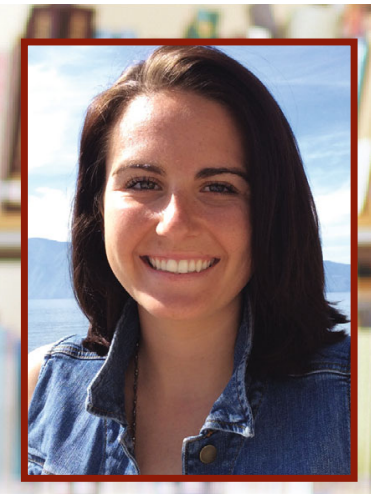

Alexandra Glover 


\section{Attention Material Advantage Members: What TMS Can Offer You}

Were you reading about these students and thinking to yourself, "That sounds like me"? Next year, it could be you! If you are a full-time sophomore or junior in a metallurgical/materials science or engineering program, you can apply for a TMS Foundation scholarship. For more information on each scholarship and how to apply, visit the TMS Professional Honors and Awards website at awards.tms.org.

Meanwhile, get active in Material Advantage. In addition to the opportunities offered by your university's chapter, you also have access to many of the professional benefits offered by TMS at discounted rates. If you have recently graduated, there's no need to worry-TMS is offering you a free professional membership for this year only. Think of it as a graduation gift from TMS to you. The TMS Foundation is also proud to support new professionals through an array of special awards and programs designed to give you a great start to your career. All of these resources and more are available at little to no cost to you. Visit http://www.tms .org/Society/ProfMembership.aspx for information on both student and recent graduate membership.

\section{STRUCTURAL MATERIALS DIVISION (SMD) SCHOLARSHIPS}

Awarded to outstanding sophomore or junior students majoring in metallurgical and/or materials science and engineering with an emphasis on the science and engineering of load-bearing materials, including studies into the nature of a material's physical properties based upon its microstructure and operating environment.

\section{Steven Zeltmann}

New York University, Brooklyn

"This award will support my studies and research in materials science and metals. This will encourage me to seek further awards from the Foundation and other societies which I can use in funding my education.
This award is a great honor to receive and will help as I pursue graduate schools and internships in the future."

\section{Shane Anderson \\ Michigan Technological University, Houghton}

"The scholarship will provide me with financial assistance, which will allow me to work fewer hours at a part-time job and focus more on my studies. It is an honor to be awarded this scholarship. This recognition gives me more confidence in what I am doing and will help push me to the next level in my academic and, eventually, professional career. It also presents me with new experiences and networking opportunities."

\section{TMS BEST PAPER CONTEST, GRADUATE DIVISION \\ First Place: Brian Lin \\ Carnegie Mellon University \\ Second Place: Cheng-Chieh Li National Taiwan University}

"Being a part of TMS as a student has been extremely rewarding. The TMS Foundation has given me the chance to travel to these conferences I previously might not have considered, and to present my work to a community that really cares about what I'm doing. This is yet another example of how the TMS Foundation enables students to shine and be passionate about their work, and for this I am incredibly thankful."
"This award truly inspires me to continue my pursuit of materials science research. I would like to thank my advisor, C. Robert Kao, National Taiwan University, who always encourages me to seize opportunities. I also very much appreciate the TMS Foundation for offering this particular opportunity. It substantially helps graduate students in developing a career."

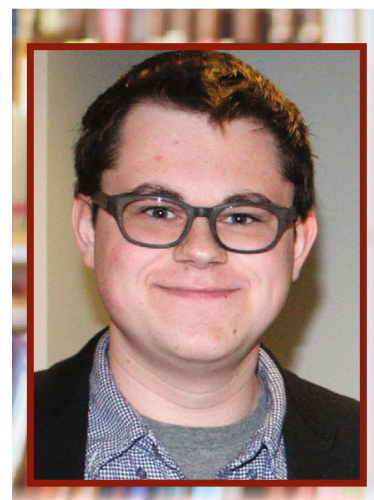

Steven Zeltmann

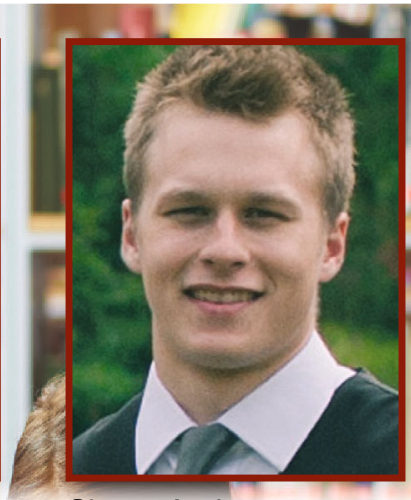

Shane Anderson

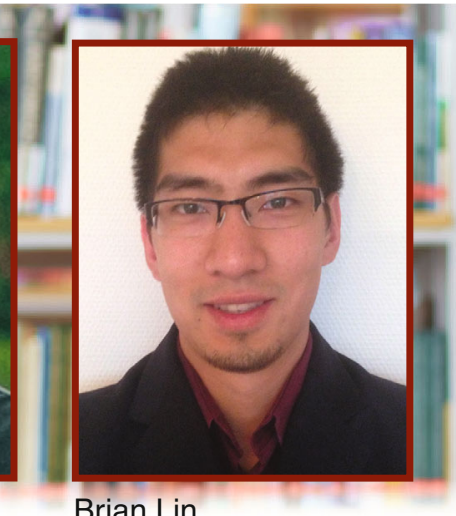

Brian Lin

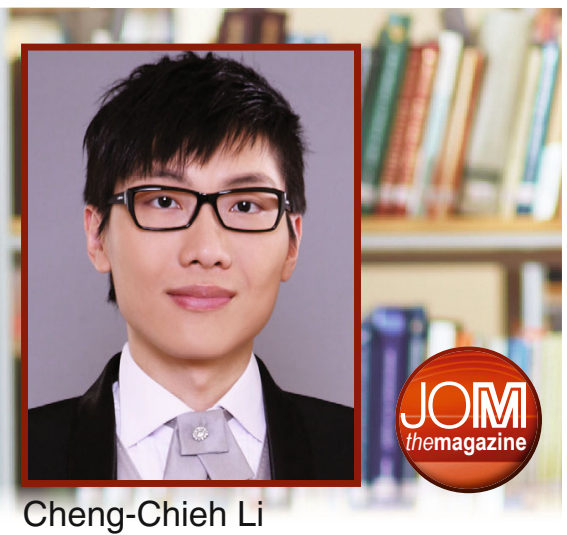

